University of Nebraska - Lincoln

DigitalCommons@University of Nebraska - Lincoln

Colonization of wounded peanut seeds by soil fungi: selectivity for species from Aspergillus section Flavi

Bruce W. Horn

USDA-ARS, bhorn@nprl.usda.gov 
Mycologia, 97(1), 2005, pp. 202-217.

(C) 2005 by The Mycological Society of America, Lawrence, KS 66044-8897

\section{Colonization of wounded peanut seeds by soil fungi: selectivity for species from Aspergillus section Flavi}

\author{
Bruce W. Horn ${ }^{1}$ \\ National Peanut Research Laboratory, Agricultural \\ Research Service, U.S. Department of Agriculture, \\ Dawson, Georgia 39842
}

\begin{abstract}
Soil is a source of primary inoculum for Aspergillus flavus and A. parasiticus, fungi that produce highly carcinogenic aflatoxins in peanuts. Aflatoxigenic fungi commonly invade peanut seeds during maturation, and the highest concentrations of aflatoxins are found in damaged seeds. A laboratory procedure was developed in which viable peanut seeds were wounded and inoculated with field soil containing natural populations of fungi, then incubated under different conditions of seed water activity and temperature. Densities of Aspergillus section Flavi in soil used for inoculating seeds were low relative to the total numbers of filamentous fungi $(<1 \%)$. Aspergillus species from section Flavi present in soil included $A$. flavus morphotypes $\mathrm{L}$ and $\mathrm{S}$ strains, A. parasiticus, A. caelatus, A. tamarii and A. alliaceus. Wounding was required for high incidences of fungal colonization; viability of wounded seeds had little effect on colonization by Aspergillus species. Peanut seeds were colonized by section Flavi species as well as $A$. niger over broad ranges of water activity (0.82-0.98) and temperature (15-37 C), and the highest incidences of seed colonization occurred at water activities of $0.92-0.96$ at $22-37$ C. A. parasiticus colonized peanut seeds at lower temperatures than A. flavus, and cool soil temperatures relative to temperatures of aerial crop fruits might explain why $A$. parasiticus is found mostly in peanuts. Other fungi, dominated by the genera Penicillium, Fusarium and Clonostachys, colonized seeds primarily at water activities and temperatures suboptimal for section Flavi species and A. niger. Eupenicillium ochrosalmoneum frequently sporulated on the conidial heads of section Flavi species and showed specificity for these fungi. The inoculation of wounded viable peanut seeds with soil containing natural populations of fungi provides a model system for studying the infection process, the interactions among fungi and those factors important in aflatoxin formation.
\end{abstract}

\footnotetext{
Accepted for publication 6 September 2004.

${ }^{1}$ E-mail: bhorn@nprl.usda.gov
}

Key words: aflatoxin, Arachis hypogaea, Aspergillus alliaceus, Aspergillus caelatus, Aspergillus flavus, Aspergillus niger, Aspergillus parasiticus, Aspergillus tamarii, competitive saprophytic ability, Eupenicillium ochrosalmoneum, fungal competition, Penicillium, water activity

\section{INTRODUCTION}

Carcinogenic aflatoxins produced by Aspergillus flavus and $A$. parasiticus are common contaminants of peanuts, corn, cottonseed and tree nuts (Diener et al 1987, Payne 1998). In Africa and southeastern Asia, aflatoxins have been shown to increase the incidence of human liver cancer by acting synergistically with hepatitis viruses (Wild and Turner 2002). In addition to the health concerns related to aflatoxins, the cost of managing aflatoxins is often very high, averaging $\$ 26$ million annually to the peanut industry in the southeastern United States alone (Lamb and Sternitzke 2001).

Aerial crops such as corn and cottonseed are infected predominantly with A. flavus, whereas peanuts (Arachis hypogaea) with their subterranean growth habit are invaded by both $A$. flavus and A. parasiticus (Horn 2003). A. flavus has been divided into two morphotypes: the typical L strain that produces large sclerotia $>400 \mu \mathrm{m}$ diam and the $\mathrm{S}$ strain, described as variety parvisclerotigenus (Saito and Tsuruta 1993), which produces numerous small sclerotia $<400 \mu \mathrm{m}$ (Cotty 1989). Other Aspergillus species belonging to section Flavi have been reported from peanuts, including A. caelatus and A. tamarii (Horn 1997, Horn and Greene 1995). Another species, A. alliaceus (teleomorph $=$ Petromyces alliaceus), has been transferred to section Flavi based on molecular characters (Peterson 2000). None of these other species forms aflatoxins, although $A$. tamarii produces cyclopiazonic acid (Horn et al 1996) and A. alliaceus produces ochratoxin A (Bayman et al 2002a).

Soil serves as a reservoir for primary inoculum of A. flavus and A. parasiticus (Horn et al 1995, Horn and Dorner 1998), and peanut pods are in direct contact with soil populations of aflatoxigenic fungi. Infection of peanut seeds predominantly by primary inoculum differs from infection of corn and cottonseed in which secondary inoculum plays a dominant 
role (Horn 2003). Two modes of infection are possible in peanuts. First, seeds from pods without visible damage may be invaded by aflatoxigenic fungi when plants are drought stressed (Sanders et al 1981), although undetected microscopic pod damage might account for some of this infection (Porter et al 1986). Second, pod and seed damage allows for direct invasion from soil. The highest levels of A. flavus and A. parasiticus infection and aflatoxin contamination are associated with seed damage (Blankenship et al 1984, Dowell et al 1990, Hill et al 1983, Sanders et al 1985b). Larvae of lesser cornstalk borer (Elasmopalpus lignosellus) scarify and penetrate peanut pods and largely are responsible for pod and seed damage in the United States (Lynch 1984, Lynch and Mack 1995, Lynch and Wilson 1991). In tropical regions where peanuts are cultivated, white grubs (scarab beetle larvae), termites and millipedes are important feeders on peanut pods (Lynch and Mack 1995). Growth cracks also may expose seeds to soil inoculum that results in an increase in fungal invasion and aflatoxins (Schroeder and Ashworth 1965).

Peanut seeds vary considerably in water activity $\left(\mathrm{A}_{\mathrm{w}}\right)$ and exposure to soil temperatures. Water activities of individual seeds range from 0.75 to 1.00 (Dorner et al 1989, JW Dorner unpublished data), and soil temperatures in the pod zone range from $20 \mathrm{C}$ in warm temperate regions to $>38 \mathrm{C}$ in semi-arid tropical areas (Craufurd et al 2003, Hill et al 1983). Peanuts are invaded by aflatoxigenic fungi primarily under conditions of late-season drought and elevated soil temperatures (Blankenship et al 1984, Hill et al 1983, Sanders et al 1981, Sanders et al 1985b).

For this study a laboratory technique was developed in which viable peanut seeds were wounded and the wound sites were inoculated with soil from the field. The effects of various factors on peanut seed colonization by Aspergillus section Flavi species from natural populations in soil, including water activity, temperature, wounding and seed viability, are reported.

\section{MATERIALS AND METHODS}

Soil collections.-Soil was collected 3 Jul, 30 Jul, 5 Sep, 13 Nov 2001; 24 Jan, 22 Feb, 3 Sep 2002; and 3 Feb, 2 Sep 2003 from cultivated Field A (1.6 km west of Graves, Terrell County, Georgia) and Field B (0.8 km south of Shellman, Randolph County). Soil consisted of Tifton loamy sand (fine-loamy, kaolinitic, thermic Plinthic Kandiudults with 0$2 \%$ slope) and Greenville sandy loam (fine, kaolinitic, thermic Rhodic Kandiudults with $0-2 \%$ slope) for Fields A and $\mathrm{B}$, respectively. Approximately $3 \mathrm{~kg}$ of soil was collected from the top $5 \mathrm{~cm}$ and thoroughly mixed. From a portion of this soil $(600 \mathrm{~g})$, three $50 \mathrm{~g}$ subsamples were removed and oven-dried (100 C, $48 \mathrm{~h}$ ) to determine moisture con- tent. The remaining soil was stored at $5 \mathrm{C}$ in sealed plastic bags and used within $3 \mathrm{wk}$ to determine fungal population densities and for inoculating seeds.

Fungal soil populations.-Aspergillus species and total filamentous fungi were enumerated, and Aspergillus species were identified as described by Horn and Dorner (1998). Briefly, three $3.3 \mathrm{~g}$ subsamples of soil were vortexed in 10 $\mathrm{mL}$ of $0.2 \%$ water agar. Soil suspensions of subsamples each were dilution plated onto five plates $(0.2 \mathrm{~mL} /$ plate $)$ of modified dichloran-rose bengal medium and incubated 3-4 d at 37 C. Species from Aspergillus section Flavi were identified under a stereomicroscope directly from the dilution plates with the exception of $A$. caelatus and A. tamarii, which were subcultured to Czapek agar $(\mathrm{Cz})$ slants for final identification. Aspergillus species from other sections not recognizable on dilution plates were subcultured and identified according to the techniques of Klich (2002) and Raper and Fennell (1965). The density of total filamentous fungi was determined on unmodified dichloran-rose bengal medium after $5 \mathrm{~d}$ at $25 \mathrm{C}$ (Horn et al 1994), and those same plates were incubated an additional 2-3 d (30 C) to enumerate Eupenicillium ochrosalmoneum (anamorph $=$ Penicillium ochrosalmoneum) and Eup. cinnamopurpureum (anamorph $=$ Pen . cinnamopurpureum). Eupenicillium species were recognized on dilution plates by colonies dominated by ascostromata; isolates were subcultured to $\mathrm{Cz}$ slants and identified according to Pitt (1979). All fungal densities were corrected for soil moisture and were reported on a dry-weight basis.

Peanut seeds.-Irrigated peanut plants of the cultivar Georgia Green were grown using standard applications of fertilizer, herbicides, fungicides and insecticides (Guillebeau 2004). Peanut plants were dug from fields on 18 Oct 2000 (7.9 km northeast of Cuthbert, Randolph County, Georgia), 13 Sep 2001 (5.4 km southwest of Dawson, Terrell County), and 8 Sep 2002 and 11 Sep 2003 (2.1 km north of Sasser, Terrell County) with a digger-inverter, and pods immediately were hand picked. Fresh pods were abraded with a wet-impact blaster to expose the inner pericarp wall, then color sorted according to maturity (Williams and Drexler 1981, Williams and Monroe 1986). Mature pods (black and brown maturity classes) were removed and dried $14 \mathrm{~d}$ at ambient temperature on a forced-air drier. Dried pods were stored at $5 \mathrm{C}$ and were used for experiments within $1 \mathrm{yr}$. At the end of $1 \mathrm{yr}$, the embryos and cotyledons of 100 seeds were tested for tissue viability after pod-surface sterilization using the tetrazolium method (Peters 2000).

Blasted pods without visible damage to the pericarp were surface sterilized 2 min with $2.0 \%$ Na hypochlorite followed by three sterile water rinses. Seeds were removed aseptically from the pods. Two seeds were placed loosely in each of two compartments of four-section plates $(100 \times 15 \mathrm{~mm})$; the other two compartments contained $4 \mathrm{~mL}$ of $\mathrm{NaCl}$ solution $\left(\mathrm{A}_{\mathrm{w}}=0.82,0.84,0.85,0.87,0.90,0.93,0.96\right)$ or distilled water $\left(\mathrm{A}_{\mathrm{w}}=1.00\right)$ with a fitted piece of filter paper to keep the solution evenly spread (FIG. 2). To adjust seeds to a specific water activity, plates were incubated $7 \mathrm{~d}$ at 37 $\mathrm{C}$ in a covered desiccator jar over $900 \mathrm{~mL}$ of the same solution. Seed water activities were up to 0.02 units below 

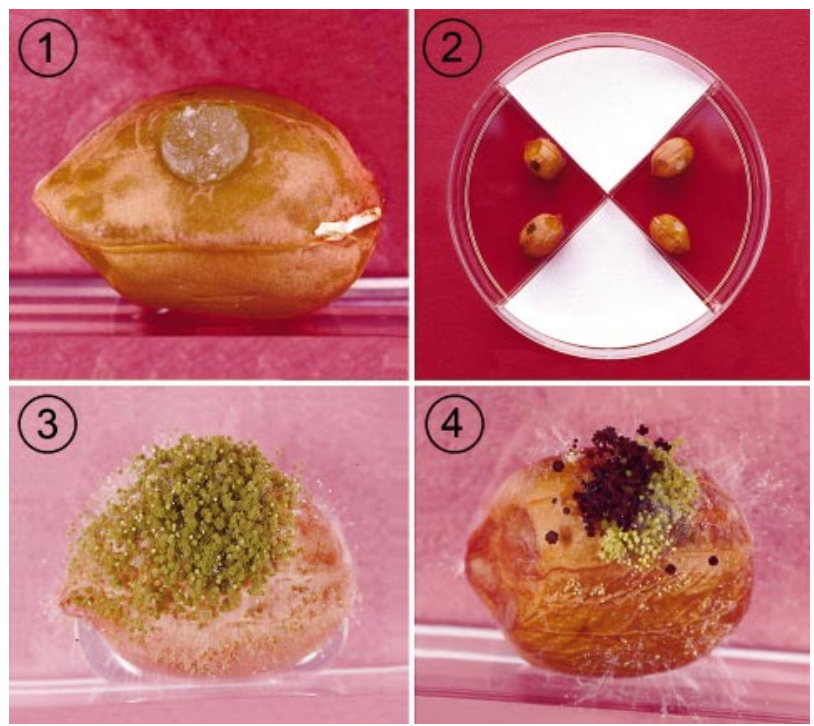

Figs. 1-4. 1. Aseptically wounded peanut seed before inoculation with soil. 2. Four-sectioned plate containing wounded peanut seeds, two of which have been inoculated with soil. Two of the compartments contain $\mathrm{NaCl}$ solution with filter paper. 3, 4. Wounded peanut seeds inoculated with soil and incubated for $7 \mathrm{~d}$ at $37 \mathrm{C}$ in a desiccator jar (salt solution $\mathrm{A}_{\mathrm{w}}=0.93$ ); seeds are colonized by Aspergillus section Flavi species and A. niger.

those of the salt solutions and water after incubation. $\mathrm{NaCl}$ solutions for specific water activities were made up according to Chirife and Resnik (1984). Water activities of solutions and peanut seeds were determined with a Series 3TE water activity meter (Decagon Devices, Pullman, Washington); seed water activities were measured at the temperature of the experiment.

Seed inoculations.-After rehydration peanut seeds were examined under the stereomicroscope for fungal growth. One cotyledon from each fungus-free seed then was injured aseptically to a depth of approximately $1 \mathrm{~mm}$ with a borer (3 $\mathrm{mm}$ diam), and the peanut tissue was scraped from the inside of the borer cut with a dissecting needle (FIG. 1). Seeds were attached to the bottom of the plate adjacent to the partitions (wound facing outward) (FIG. 2) using multitemperature glue applied with a small glue gun.

For inoculating seeds, $33 \mathrm{~g}$ of soil was mixed with $3.0-$ $6.5 \mathrm{~mL}$ of sterile water (depending on the initial moisture content of the soil) to form a near-saturated paste. Wound sites from 40 peanut seeds (10 plates) then were inoculated with $7.2 \pm 0.002 \mathrm{mg}$ of soil ( $\pm \mathrm{SD} ; \mathrm{n}=20$; dry weight) using a small spatula. An additional 20 wounded seeds in each experiment were not inoculated and served as controls. Twenty seeds that were not wounded or inoculated also were included in each experiment; those seeds were macerated individually with a razor blade at the time of inoculation ( $7 \mathrm{~d}$ incubation) (10 seeds) and at the end of the experiment (10 seeds) for determining water activities.

Fungal colonization.-Peanut seeds were examined under the stereomicroscope at 4, 7 and $14 \mathrm{~d}$ after inoculation with soil. Additional periods of incubation of up to $42 \mathrm{~d}$ were required for experiments involving low water activities and/ or low temperatures that slowed the rate of fungal growth. At the end of the experiments, the extent of colonization by section Flavi was estimated as $0-100 \%$ of the visible seed surface. A. niger, A. terreus and Emericella rugulosa (anamorph $=$ A. rugulovalvus) were identified directly from the peanut seed. Aspergillus species from section Flavi, with the exception of $A$. alliaceus, could not be distinguished based on conidial color when growing on peanut seeds and, therefore, were subcultured onto $\mathrm{Cz}$ slants for identification. One to 10 transfers were made from each seed, depending on the extent of colonization by section Flavi. Eupenicillium species, when present on the heads of species from section Flavi, were transferred simultaneously with their hosts to $\mathrm{Cz}$ slants where they typically continued to sporulate on the Aspergillus heads. Other fungal species that could not be identified directly on the seeds were subcultured and identified according to these references for each genus: Aspergillus and its teleomorphs Petromyces, Emericella and Eurotium (Klich 2002, Raper and Fennell 1965); Penicillium and its teleomorphs Eupenicillium and Talaromyces (Pitt 1979); Paecilomyces (Samson 1974); Fusarium (Nelson et al 1983); Clonostachys (Schroers 2001); Alternaria and Cladosporium (Ellis 1971); Absidia and Syncephalastrum (Domsch et al 1980); Cunninghamella (Zheng and Chen 2001); Rhizopus (Schipper and Stalpers 1984); and Thermomucor (Subrahamanyam et al 1977).

Other experiments.-Colonization of fresh seeds obtained directly from the field was compared with colonization of dried peanut seeds revived in water. Fresh pods from the field were abraded for color sorting, surface sterilized and shelled without drying. Dried seeds from surface-sterilized pods were revived to the water activity of fresh seeds by soaking in sterile water $(16 \mathrm{~h}$ at $5 \mathrm{C})$. Forty seeds from each set were wounded and inoculated with soil from Field A. Inoculated seeds were incubated $14 \mathrm{~d}$ at $37 \mathrm{C}$ over salt solution $\left(\mathrm{A}_{\mathrm{w}}=0.89\right)$ as previously described. The experiment was performed twice.

The effects of wounding and seed viability on colonization also were examined together in a combined experiment. Treatments included: (i) viable seeds, wounded; (ii) viable seeds, not wounded; (iii) nonviable seeds, wounded; and (iv) nonviable seeds, not wounded. Unwounded seeds (viable and nonviable) were inoculated at one of three locations on the seed surface: (i) cotyledon where normally wounded; (ii) raphe midway between the hilum and chalaza; and (iii) hilum. All treatments, including inoculations at three locations on the seed, were represented by 40 seeds. Dried seeds were rendered nonviable by autoclaving $1 \mathrm{~min}$ at $120 \mathrm{C}$. All seeds were rehydrated in desiccator jars over salt solution $\left(\mathrm{A}_{\mathrm{w}}=0.96\right)$ at $37 \mathrm{C}$ for $7 \mathrm{~d}$. Fungus-free seeds then were inoculated with soil from Field A and incubated $14 \mathrm{~d}$ under the same conditions. The experiment was performed twice.

In another experiment, different seeds and grain ( $\mathrm{n}=$ 40) were wounded and inoculated with soil from Field A to determine their susceptibility to invasion by Aspergillus species. Brazil nuts, unsplit pistachio nuts (Kermit cultivar), 
TABle I. Populations of Aspergillus species and their teleomorphs in soil used for inoculating peanut seeds

\begin{tabular}{|c|c|c|c|c|}
\hline \multirow[b]{2}{*}{ Aspergillus species ${ }^{\mathrm{b}}$} & \multicolumn{2}{|c|}{ Field $A^{a}$} & \multicolumn{2}{|c|}{ Field $B^{a}$} \\
\hline & $\mathrm{CFU} / \mathrm{g}$ & Relative density $^{c}$ & $\mathrm{CFU} / \mathrm{g}$ & Relative density ${ }^{c}$ \\
\hline \multicolumn{5}{|l|}{ Section Flavi } \\
\hline A. flavus L strain & $461 \pm 141.4$ & $33 \pm 7.1$ & $1301 \pm 1717.8$ & $41 \pm 22.7$ \\
\hline A. flavus $\mathrm{S}$ strain & $136 \pm 63.8$ & $10 \pm 3.4$ & $7 \pm 11.1$ & $0.1 \pm 0.20$ \\
\hline A. parasiticus & $178 \pm 103.3$ & $11 \pm 4.6$ & $532 \pm 407.0$ & $34 \pm 15.7$ \\
\hline A. caelatus & $273 \pm 163.1$ & $18 \pm 3.0$ & $359 \pm 259.8$ & $20 \pm 9.0$ \\
\hline A. tamarii & $81 \pm 67.8$ & $5 \pm 1.2$ & $86 \pm 89.7$ & $5 \pm 3.1$ \\
\hline A. alliaceus & $371 \pm 319.2$ & $23 \pm 6.1$ & $0 \pm 0.0$ & $0 \pm 0.0$ \\
\hline \multicolumn{5}{|l|}{ Section Nigri } \\
\hline A. niger & $2919 \pm 1025.0$ & & $3430 \pm 2502.8$ & \\
\hline A. japonicus & $4 \pm 5.4$ & & $2 \pm 3.6$ & \\
\hline \multicolumn{5}{|l|}{ Section Terrei } \\
\hline A. terreus & $7549 \pm 2818.9$ & & $10512 \pm 12694.4$ & \\
\hline A. carneus & $111 \pm 76.2$ & & $3 \pm 5.6$ & \\
\hline \multicolumn{5}{|l|}{ Section Nidulantes } \\
\hline Emericella rugulosa & $115 \pm 66.0$ & & $1093 \pm 1880.8$ & \\
\hline A. ustus & $10 \pm 16.2$ & & $55 \pm 70.3$ & \\
\hline \multicolumn{5}{|l|}{ Section Fumigati } \\
\hline A. fumigatus & $607 \pm 440.0$ & & $9545 \pm 4124.8$ & \\
\hline $\begin{array}{l}\text { Total filamentous fungi } \\
\left(\times 10^{5}\right)\end{array}$ & $1.27 \pm 0.364$ & & $1.72 \pm 1.065$ & \\
\hline
\end{tabular}

${ }^{a}$ Mean \pm SD based on five independent soil collections.

${ }^{\mathrm{b}}$ Deposition of species into sections according to Peterson (2000).

${ }^{\mathrm{c}}$ Percentage of section Flavi.

English walnuts (Chandler), shelled almonds (Nonpareil), cottonseed (Deltapine 458BR, acid delinted), corn (Pioneer 3394) and soybeans (Northrup King S73-Z5) were surface sterilized as described for peanuts. Brazil nuts, pistachio nuts and English walnuts were shelled aseptically after surface sterilization. These three nuts and almonds were wounded with a borer in the same manner as peanuts. A sterile scalpel was used to slice off a portion $(<1 \mathrm{~mm})$ of cottonseed, corn kernels and soybeans at the end opposite of the germ. Because of the high incidence of fungi in some of the seeds and grain that were not killed by surface sterilization (particularly in English walnuts, almonds and corn), seeds and grain were not rehydrated beforehand but instead were wounded in a dry state before inoculation with soil from Field A. Inoculated seeds and grain were incubated in desiccator jars over salt solution $\left(\mathrm{A}_{\mathrm{w}}=0.96\right)$ at $37 \mathrm{C}$ for $14 \mathrm{~d}$. The water activity was determined from 10 individual seeds and corn kernels (not wounded or inoculated) at the end of the experiment.

Statistics.—Data were analyzed using SigmaStat, version 1.0 (Jandel Scientific, San Rafael, California).

\section{RESULTS}

Soil populations.-Fresh soil was collected for each experiment to ensure the viability of all possible fungal colonizers of peanut seeds. As a consequence, fungal densities in soil from a given field varied considerably because of different collection dates (TABLE I). Fields A and B differed in both composition and density of species belonging to Aspergillus section Flavi. Field A contained A. alliaceus, not detected in Field B, and Field B had higher densities of A. flavus $\mathrm{L}$ strain and A. parasiticus than Field A. A. flavus $\mathrm{S}$ strain was rare in Field B soil. Aspergillus species present at the highest densities included $A$. niger and $A$. terreus in Fields A and B and A. fumigatus in Field B. In both fields the relative density (percentage of total filamentous fungi) of combined species from section Flavi was $<1 \%$.

Seed viability and initial infection rate-Cotyledon and embryo tissue in peanut seeds (100 seeds each for harvest years 2000, 2001 and 2002) were 100\% viable based on the tetrazolium test. Of the wounded control seeds that were not inoculated with soil $(\mathrm{n}=$ 752), two seeds showed fungal colonization (A. niger and Pen. pinophilum) at the end of the experiments and none was infected with species from Aspergillus section Flavi.

Comparison of fresh and rehydrated peanut seeds.-The water activities of peanut seeds $( \pm \mathrm{SD}, \mathrm{n}=10)$ at 
inoculation were similar for fresh seeds (0.99 \pm $0.002)$ and rehydrated seeds $(0.99 \pm 0.002)$ in Experiment 1 and for fresh seeds $(0.99 \pm 0.001)$ and rehydrated seeds $(0.98 \pm 0.006)$ in Replicate Experiment 2. The incidence of section Flavi was $87.5 \%$ for both fresh and rehydrated seeds in Experiment 1 and $90.0 \%$ for both fresh and rehydrated seeds in Experiment 2. The respective incidences of $A$. niger in fresh and rehydrated seeds were 50.0 and $47.5 \%$ in Experiment 1 and 30.0 and $32.5 \%$ in Experiment 2.

Interactions of water activity and temperature.-Colonization of wounded viable peanut seeds (rehydrated) after inoculation with soil often was dominated by species from Aspergillus section Flavi and A. niger (FIGS. 3, 4). Application of soil from Fields A and B to wounds resulted in similar patterns of peanut seed colonization by A. flavus L strain (FIG. 5), A. parasiticus (FIG. 7), A. tamarii (FIG. 8) and A. caelatus (FIG. 9) over the range of water activities and temperatures tested. A. flavus S strain and A. alliaceus occurred at low densities or were not detected in soil from Field B (TABLE I); therefore seeds inoculated with Field B soil were not colonized by either of these species (Figs. 6, 10). Within the $14 \mathrm{~d}$ incubation period after inoculation, all species from section Flavi colonized seeds within similar limits of seed water activity (0.82-0.98) and temperature (22-37 C) (FIGS. 5-10). The highest incidences of colonization by $A$. flavus $\mathrm{L}$ and $\mathrm{S}$ strains, A. tamarii and A. alliaceus generally occurred at seed water activities of 0.92 and 0.96 and temperatures of 30 and 37 C. A. parasiticus showed high incidences of colonization at $22 \mathrm{C}$ (FIG. 7 ), and A. caelatus showed an increasing incidence of colonization with decreasing temperature (maximum of $17.9 \%$ at $37 \mathrm{C}$ to $64.3 \%$ at $22 \mathrm{C}$ ) (FIG. 9). Increasing temperatures from 22 to $37 \mathrm{C}$ also resulted in an increase in the ability of species to colonize peanuts at lower water activities (FIGS. 5-10).

The extent of seed colonization by Aspergillus section Flavi, measured as a percentage of the visible seed surface, increased with increasing water activity and temperature to optimal conditions of $\mathrm{A}_{\mathrm{w}}=0.96$ at $37 \mathrm{C}$ (73.4 and $81.4 \%$ of the seed surface for Fields $\mathrm{A}$ and $\mathrm{B}$ respectively). However colonization by section Flavi at a seed water activity of 0.98 accounted for only 8.0 and $10.1 \%$ of the seed surface at $37 \mathrm{C}$ for respective Fields $\mathrm{A}$ and $\mathrm{B}$, and growth of fungi in general similarly was inhibited at all temperatures at this water activity.

Incubation of seeds at lower water activities for periods of greater than $14 \mathrm{~d}$ showed slow increases in the incidence of seed colonization by section Flavi (FIG. 11). Highest incidences of colonization by sec- tion Flavi generally were attained with $14 \mathrm{~d}$ incubation ( $\operatorname{seed} \mathrm{A}_{\mathrm{w}}=0.96$ ) at 22, 30 and $37 \mathrm{C}$ (FIG. 12). However at $15 \mathrm{C}$ with seeds inoculated with Field B soil, the incidence of colonization by section Flavi increased from $0.0 \%$ at $14 \mathrm{~d}$ to $64.3 \%$ at $28 \mathrm{~d}$. This increase was due solely to $A$. parasiticus. Similarly $A$. parasiticus was the only colonizer from section Flavi (14.3\%) after $35 \mathrm{~d}$ incubation at $15 \mathrm{C}\left(\operatorname{seed} \mathrm{A}_{\mathrm{w}}=\right.$ 0.93 ) when seeds were inoculated with soil from Field A.

Colonization of seeds by A. niger (FIG. 13) occurred at water activities and temperatures similar to those for section Flavi species. In contrast A. terreus showed high incidences of colonization at $45 \mathrm{C}$ (FIG. 14). Although A. terreus colonized a high proportion of seeds at 30 and $37 \mathrm{C}$, this slow-growing species generally was restricted to the wound site after $4 \mathrm{~d}$ of incubation and quickly was overrun thereafter by more aggressive section Flavi species and A. niger. At $45 \mathrm{C}$, the lack of competition with section Flavi species and $A$. niger allowed $A$. terreus to more fully colonize the seeds.

Other species of fungi, with the exception of Eup. ochrosalmoneum, were observed most frequently on peanut seeds under conditions of water activity and temperature that were suboptimal for colonization by section Flavi species and A. niger (TABLE II). Penicillium species were generally most common at lower seed water activities $(\leq 0.89)$ and lower temperatures (15, 22 C) except for Pen. pinophilum and Pen. funiculosum, which occurred only at the highest seed water activity of 0.98. Species of Fusarium, Clonostachys, Paecilomyces, Alternaria, Cladosporium, Cunninghamella and Syncephalastrum occurred at higher seed water activities $(\geq 0.92)$ and lower temperatures (15, 22 C). A. fumigatus and Talaromyces species colonized seeds primarily at $37 \mathrm{C}$ with a seed water activity of 0.98. Growth at $45 \mathrm{C}$ mostly was restricted to $A$. terreus (FIG. 14), Em. rugulosa, Rhizopus microsporus and Thermomucor indicae-seudaticae.

Effects of wounding and seed viability.-Water activities of viable and nonviable (autoclaved) seeds $(\mathrm{n}=10)$ at the time of inoculation were not significantly different $(t$-test; $P>0.05)$ within each of the two replicated experiments ( seed $\mathrm{A}_{\mathrm{w}}=0.95$ ). The incidences of Aspergillus species on viable wounded seeds were considerably greater than the incidences on viable unwounded seeds (TABLE III). The location of inoculation (cotyledon, raphe or hilum) on viable unwounded seeds had no apparent effect on colonization. Although the incidence of A. terreus was high on viable unwounded seeds, colonization was confined to the area of soil application and consisted of sparse mycelium with few conidial heads. Only $2.9 \%$ 

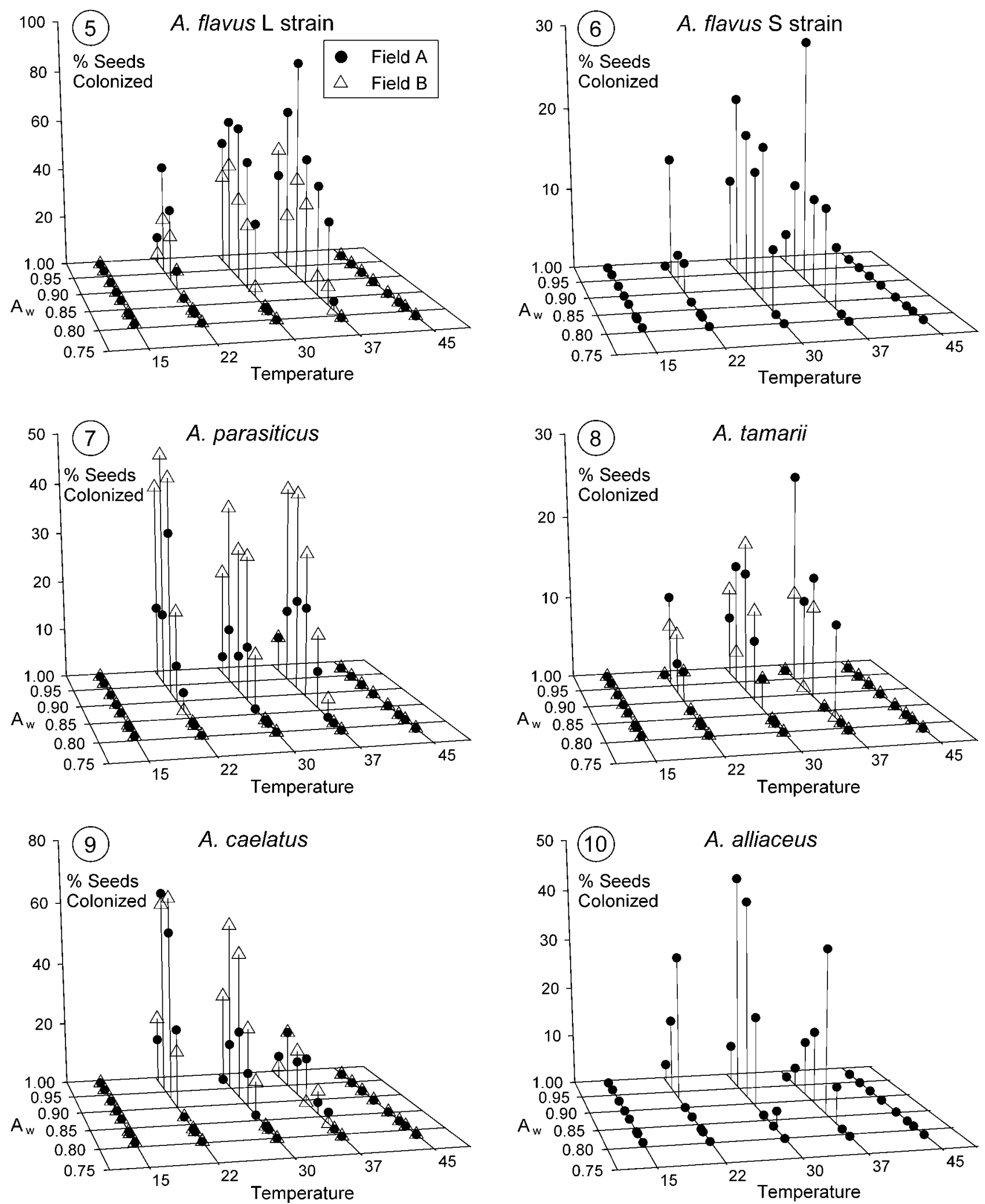

FIGS. 5-10. Percentages of wounded viable peanut seeds $(\mathrm{n}=40)$ colonized by species from Aspergillus section Flavi at different combinations of seed water activity and temperature. Wounds were inoculated with soil from Fields A and B, and seeds were subsequently incubated for $14 \mathrm{~d}$. 5. A. flavus $\mathrm{L}$ strain. 6. A. flavus $\mathrm{S}$ strain; colonization was not observed with soil from Field B. 7. A. parasiticus. 8. A. tamarii. 9. A. caelatus. 10. A. alliaceus; colonization was not observed with soil from Field B. 


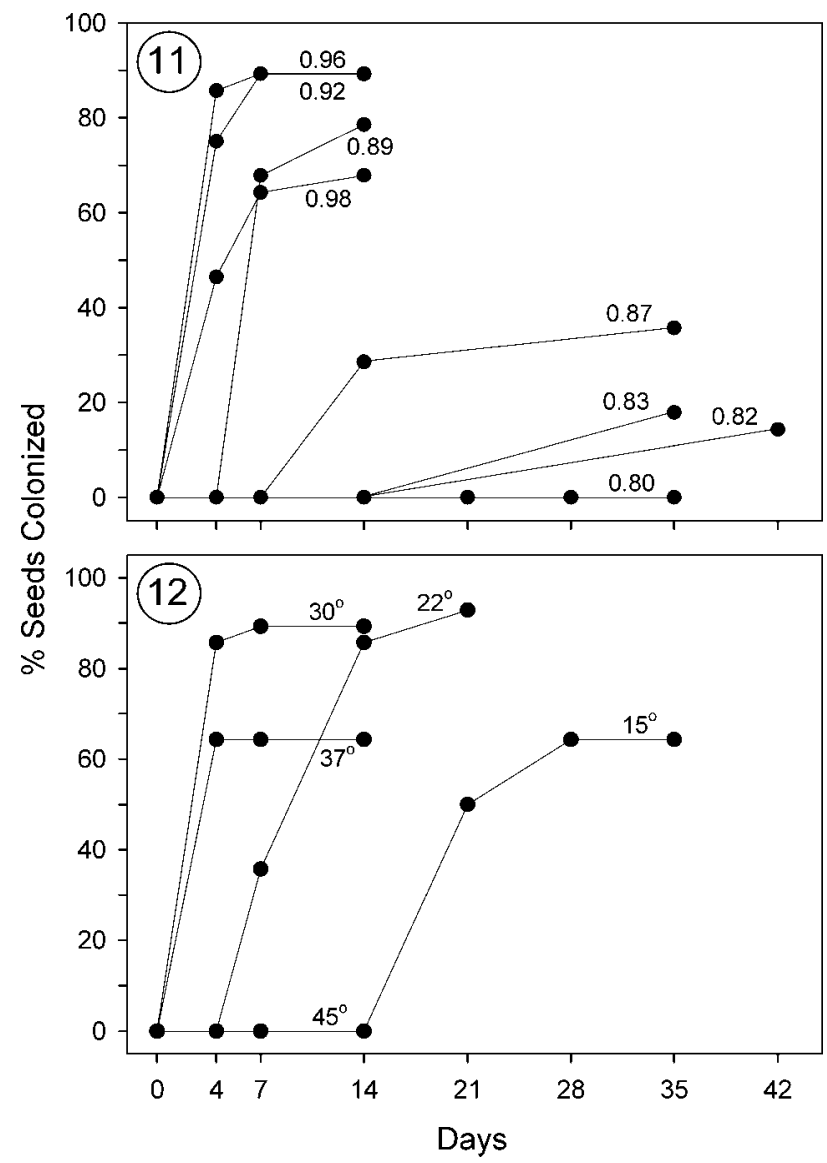

Figs. 11, 12. Effect of incubation time on colonization by combined species within Aspergillus section Flavi of wounded peanut seeds $(n=40)$ inoculated with soil from Field B. 11. Percentages of seeds colonized at different seed water activities $(30 \mathrm{C})$. 12. Percentages of seeds colonized at different temperatures (seed $\left.\mathrm{A}_{\mathrm{w}}=0.96\right)$. The increase in colonization at $15 \mathrm{C}$ was entirely due to $A$. parasiticus.

of viable unwounded seeds from both experiments $(\mathrm{n}=240)$ showed extensive colonization $(>50 \%$ visible seed surface) by section Flavi species and $A$. niger.

Loss of seed viability through autoclaving coupled with wounding resulted in little overall change in the incidences of colonization shown in viable wounded seeds (TABLE III). The respective incidences of section Flavi in nonviable wounded seeds and viable wounded seeds were 82.5 and $95.0 \%$ in Experiment 1 and 65.9 and $60.0 \%$ in Experiment 2. In contrast, inoculation of unwounded seeds with soil showed a higher overall incidence of Aspergillus species in nonviable seeds compared to viable seeds, particularly for A. niger and Em. rugulosa. In Experiment 1, for example, $A$. niger occurred on $50.0-67.5 \%$ of nonviable unwounded seeds compared to $0.0-5.0 \%$ of viable unwounded seeds and Em. rugulosa occurred on $55.0-72.5 \%$ of nonviable unwounded seeds com-
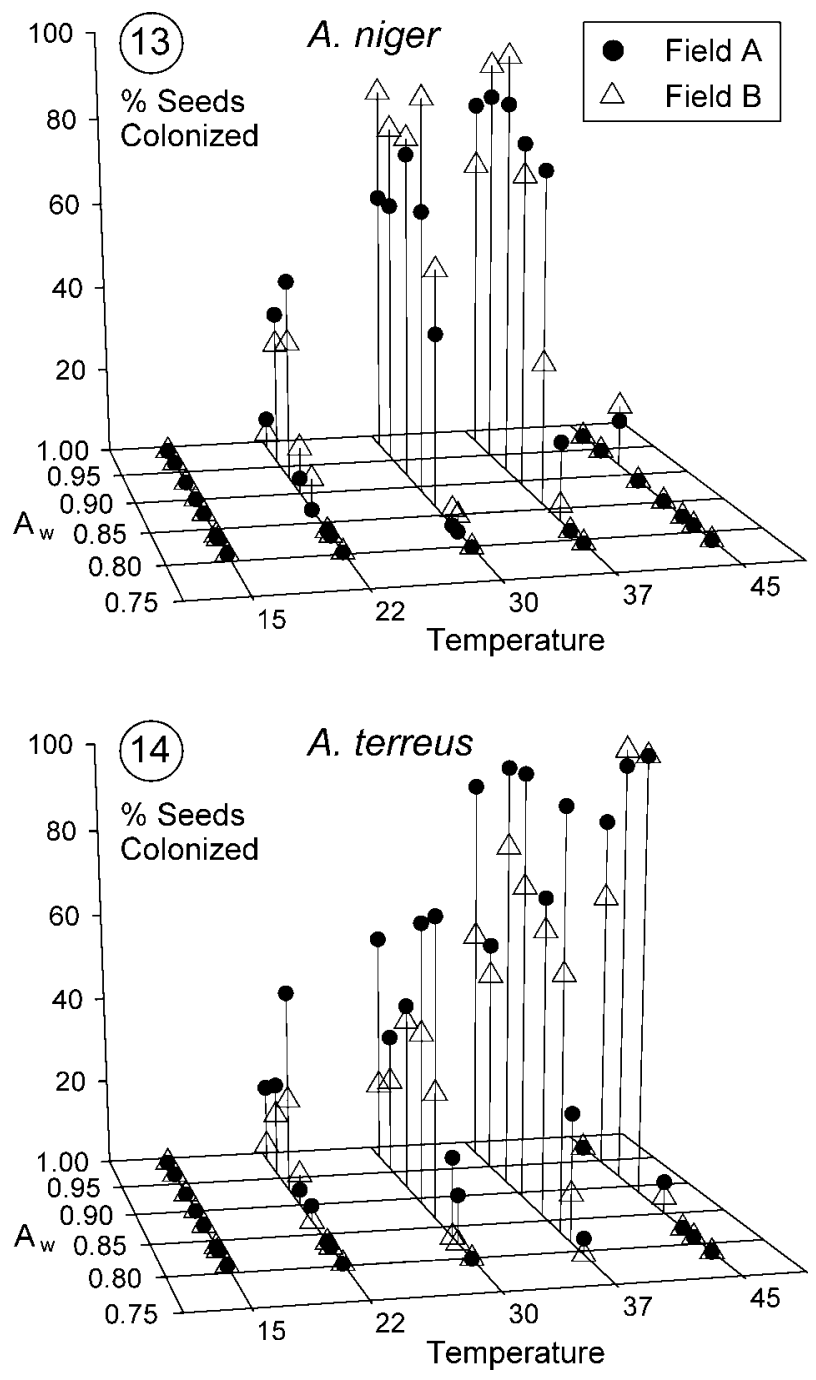

FIGS. 13, 14. Percentages of wounded viable peanut seeds $(n=40)$ colonized at different combinations of seed water activity and temperature. Wounds were inoculated with soil from Fields A and B, and seeds were subsequently incubated for 14 d. 13. A. niger. 14. A. terreus.

pared to $0.0 \%$ of viable unwounded seeds. Colonization was extensive when nonviable unwounded seeds were invaded by Aspergillus species, including A. terreus. The location of inoculation (cotyledon, raphe or hilum) had no apparent effect on colonization of nonviable unwounded seeds.

Other seeds and grain.-Wounded uninoculated seeds and grain (controls, $\mathrm{n}=20$ ) showed varying degrees of fungal colonization despite surface sterilization: almonds $(95.0 \%)$, corn $(80.0 \%)$, English walnuts $(45.0 \%)$, pistachio nuts $(15.0 \%)$, Brazil nuts $(10.0 \%)$, cottonseed $(5.0 \%)$, soybeans $(5.0 \%)$ and peanuts $(0.0 \%)$. However only one seed each of almond and walnut and two corn kernels showed colonization by species from section Flavi (all A. flavus L strain). 
TABLE II. Other fungal species colonizing peanut seeds that were wounded and inoculated with soil ${ }^{\mathrm{a}}$

\begin{tabular}{|c|c|c|c|}
\hline & Temperature & Seed water activity & $\begin{array}{c}\text { Maximum \% } \\
\text { seeds colonized }^{\mathrm{b}}\end{array}$ \\
\hline \multicolumn{4}{|l|}{ ASCOMYCOTA } \\
\hline Alternaria alternata & $15,22,30$ & $0.89,0.92, \mathbf{0 . 9 6}, 0.98$ & $17.9(\mathrm{~B})$ \\
\hline Aspergillus carneus & $\mathbf{3 0}, 37$ & $0.82, \mathbf{0 . 8 6}, \mathbf{0 . 8 9}$ & $7.1(\mathrm{~A})$ \\
\hline A. flavipes & 15 & 0.89 & $3.6(\mathrm{~B})$ \\
\hline A. fumigatus & $22,30,37,45$ & $0.96, \mathbf{0 . 9 8}$ & $89.3(\mathrm{~B})$ \\
\hline A. melleus & 15,22 & $0.86,0.89,0.92$ & $3.6(\mathrm{~A}, \mathrm{~B})$ \\
\hline A. penicillioides & 22 & 0.82 & $3.6(\mathrm{~A})$ \\
\hline A. restrictus & 15,22 & $0.83,0.92$ & $3.6(\mathrm{~A})$ \\
\hline A. ustus & $22, \mathbf{3 0}, 37$ & $0.92,0.96, \mathbf{0 . 9 8}$ & $7.1(\mathrm{~B})$ \\
\hline A. wentii & $15,22,30$ & $0.86,0.89,0.92,0.96$ & $3.6(\mathrm{~A}, \mathrm{~B})$ \\
\hline Cladosporium cladosporioides & 15,22 & $0.89, \mathbf{0 . 9 2}, 0.98$ & $25.0(\mathrm{~B})$ \\
\hline C. sphaerospermum & 15 & $0.89,0.92, \mathbf{0 . 9 6}, 0.98$ & $7.1(\mathrm{~A})$ \\
\hline Clonostachys rosea $\mathrm{f}$. catenulata & $\mathbf{2 2}, 30$ & 0.98 & $50.0(\mathrm{~B})$ \\
\hline C. rosea f. rosea & $15,22,30$ & 0.98 & $57.1(\mathrm{~B})$ \\
\hline Emericella rugulosa & $30,37,45$ & $0.82,0.86,0.89,0.92, \mathbf{0 . 9 6}$ & $64.3(\mathrm{~B})$ \\
\hline Eupenicillium cinnamopurpureum & 22, 30 & $0.83, \mathbf{0 . 8 9}, 0.96$ & $7.1(\mathrm{~A})$ \\
\hline Eup. ochrosalmoneum & $22, \mathbf{3 0}, 37$ & $0.83,0.86,0.89, \mathbf{0 . 9 2}, \mathbf{0 . 9 6}, 0.98$ & $96.4(\mathrm{~A})$ \\
\hline Eurotium amstelodami & 22 & $0.89,0.96$ & $3.6(\mathrm{~A}, \mathrm{~B})$ \\
\hline E. chevalieri & $15,22,30,37$ & $\mathbf{0 . 8 0}, 0.82,0.83,0.86,0.89, \mathbf{0 . 9 2}$ & $14.3(\mathrm{~A}, \mathrm{~B})$ \\
\hline E. repens & 15,22 & $0.83, \mathbf{0 . 8 6}, 0.92,0.96$ & $7.1(\mathrm{~A}, \mathrm{~B})$ \\
\hline E. rubrum & 22 & $0.80, \mathbf{0 . 8 9}$ & $7.1(\mathrm{~A})$ \\
\hline Fusarium acuminatum & $\mathbf{1 5}, 22,30$ & $0.92,0.96, \mathbf{0 . 9 8}$ & $78.6(\mathrm{~A})$ \\
\hline F. equiseti & $15,22,30$ & $0.89,0.92, \mathbf{0 . 9 6}, 0.98$ & $28.6(\mathrm{~B})$ \\
\hline F. oxysporum & $15,22,30$ & $0.92,0.96, \mathbf{0 . 9 8}$ & $17.9(\mathrm{~A})$ \\
\hline F. proliferatum & $15,22,30$ & $0.96,0.98$ & $3.6(\mathrm{~A}, \mathrm{~B})$ \\
\hline F. solani & $15, \mathbf{2 2}, 30$ & $0.96, \mathbf{0 . 9 8}$ & $25.0(\mathrm{~A}, \mathrm{~B})$ \\
\hline Paecilomyces sp. & $15,22,30$ & 0.98 & $28.6(\mathrm{~A})$ \\
\hline Penicillium brevicompactum & 15,22 & $0.82,0.83,0.86, \mathbf{0 . 8 9}, 0.92,0.96$ & $42.9(\mathrm{~B})$ \\
\hline Pen. citrinum & $15,22,30,37$ & $0.80,0.82,0.83, \mathbf{0 . 8 6}, 0.89,0.92,0.96,0.98$ & $39.3(\mathrm{~A})$ \\
\hline Pen. corylophilum & $15,22,30$ & $0.82,0.83,0.86, \mathbf{0 . 8 9}, 0.92,0.96,0.98$ & $35.7(\mathrm{~A})$ \\
\hline Pen. funiculosum & $22,30,37$ & 0.98 & $35.7(\mathrm{~B})$ \\
\hline Pen. glabrum & 15,22 & $0.86, \mathbf{0 . 8 9}, \mathbf{0 . 9 2}, 0.96,0.98$ & $10.7(\mathrm{~B})$ \\
\hline Pen. pinophilum & $22, \mathbf{3 0}, 37$ & 0.98 & $82.1(\mathrm{~A})$ \\
\hline Pen. cf. roseopurpureum & 15,22 & $0.82,0.83, \mathbf{0 . 8 6}, 0.89,0.92$ & $10.7(\mathrm{~B})$ \\
\hline Pen. restrictum & $15,22,30$ & $0.80,0.82,0.83,0.86, \mathbf{0 . 8 9}$ & $25.0(\mathrm{~A})$ \\
\hline Pen. sclerotiorum & 15,22 & $\mathbf{0 . 8 9}, 0.92,0.96,0.98$ & $7.1(\mathrm{~B})$ \\
\hline Pen. cf. vinaceum & $15,22,30,37$ & $0.80,0.82, \mathbf{0 . 8 3}, 0.86,0.89,0.92$ & $50.0(\mathrm{~B})$ \\
\hline Talaromyces flavus & $22,30,37$ & $0.96, \mathbf{0 . 9 8}$ & $92.9(\mathrm{~A})$ \\
\hline T. trachyspermus & 37 & 0.98 & $3.6(\mathrm{~B})$ \\
\hline \multicolumn{4}{|l|}{ ZYGOMYCOTA } \\
\hline Cunninghamella echinulata & 15,30 & $0.96, \mathbf{0 . 9 8}$ & $17.9(\mathrm{~B})$ \\
\hline C. elegans & 22,37 & 0.98 & $7.1(\mathrm{~A})$ \\
\hline Rhizopus microsporus & $15,22,30,37,45$ & $0.96, \mathbf{0 . 9 8}$ & $100.0(\mathrm{~B})$ \\
\hline Syncephalastrum racemosum & 15,22 & $\mathbf{0 . 9 2}, 0.96,0.98$ & $14.3(\mathrm{~B})$ \\
\hline Thermomucor indicae-seudaticae & 45 & $\mathbf{0 . 9 2}, 0.96$ & $14.3(\mathrm{~A})$ \\
\hline
\end{tabular}

${ }^{a}$ Based on maximum incubation periods (14-42 d).

${ }^{\mathrm{b}}$ Maximum percentage of seeds colonized based on temperatures and water activities in bold. Soil from Field A and/or Field B shown in parentheses.

Therefore the source of infection by these fungi in inoculated seeds and grain was primarily soil. The incidence of colonization in inoculated seeds and grain $(\mathrm{n}=40)$ by Aspergillus section Flavi, which in- cluded all species present in soil from Field A $(A$. flavus $\mathrm{L}$ and $\mathrm{S}$ strains, A. parasiticus, A. tamarii, A. caelatus and A. alliaceus), was: almonds (97.5\%), peanuts $(90.0 \%)$, pistachio nuts $(77.5 \%)$, soybeans 
TABLE III. Effect of peanut seed viability and wounding on incidence of fungal colonization ${ }^{\text {ab }}$

\begin{tabular}{|c|c|c|c|c|c|c|c|c|c|c|c|c|}
\hline & & & & & & & & & \multicolumn{4}{|c|}{ Other fungi } \\
\hline \multicolumn{3}{|c|}{ Peanut seed } & \multicolumn{6}{|c|}{ Section Flavi } & \multirow[b]{2}{*}{ A. niger } & \multirow[b]{2}{*}{$\begin{array}{c}\text { A. ter- } \\
\text { reus }\end{array}$} & \multirow[b]{2}{*}{$\begin{array}{c}\text { Em. } \\
\text { rugulosa }\end{array}$} & \multirow{2}{*}{$\begin{array}{l}\text { Eup. } \\
\text { ochro- } \\
\text { salmo- } \\
\text { neum }\end{array}$} \\
\hline Viable & $\begin{array}{l}\text { Wound- } \\
\text { ed }\end{array}$ & $\begin{array}{l}\text { Loca- } \\
\text { tion }^{c}\end{array}$ & $\begin{array}{l}\text { A. flavus } \\
\text { L strain }\end{array}$ & $\begin{array}{l}\text { A. flavus } \\
\text { S strain }\end{array}$ & $\begin{array}{l}\text { A. para- } \\
\text { siticus }\end{array}$ & $\begin{array}{c}\text { A. caela } \\
\text { tus }\end{array}$ & $\begin{array}{l}\text { A. } \begin{array}{l}\text { tama- } \\
\text { rii }\end{array}\end{array}$ & $\begin{array}{c}\text { A. alli- } \\
\text { aceus }\end{array}$ & & & & \\
\hline \multicolumn{13}{|c|}{ Experiment 1} \\
\hline+ & + & $\mathrm{C}$ & 50.0 & 10.0 & 25.0 & 25.0 & 2.5 & 27.5 & 100.0 & 70.0 & 32.5 & 52.5 \\
\hline \multirow[t]{3}{*}{+} & - & $\mathrm{C}$ & 0.0 & 2.5 & 2.5 & 0.0 & 0.0 & 0.0 & 0.0 & 100.0 & 0.0 & 0.0 \\
\hline & & $\mathrm{R}$ & 2.5 & 0.0 & 0.0 & 0.0 & 0.0 & 0.0 & 0.0 & 100.0 & 0.0 & 0.0 \\
\hline & & $\mathrm{H}$ & 0.0 & 0.0 & 0.0 & 2.5 & 2.5 & 0.0 & 5.0 & 100.0 & 0.0 & 0.0 \\
\hline- & + & $\mathrm{C}$ & 30.0 & 17.5 & 15.0 & 27.5 & 12.5 & 20.0 & 87.5 & 77.5 & 67.5 & 10.0 \\
\hline \multirow[t]{3}{*}{-} & - & $\mathrm{C}$ & 12.5 & 0.0 & 5.0 & 2.5 & 0.0 & 5.0 & 67.5 & 100.0 & 60.0 & 0.0 \\
\hline & & $\mathrm{R}$ & 7.5 & 10.0 & 7.5 & 5.0 & 7.5 & 2.5 & 50.0 & 95.0 & 55.0 & 0.0 \\
\hline & & $\mathrm{H}$ & 10.0 & 2.5 & 15.0 & 12.5 & 5.0 & 2.5 & 52.5 & 100.0 & 72.5 & 0.0 \\
\hline \multicolumn{13}{|c|}{ Experiment 2} \\
\hline+ & + & $\mathrm{C}$ & 22.5 & 12.5 & 7.5 & 15.0 & 7.5 & 20.0 & 95.0 & 85.0 & 22.5 & 30.0 \\
\hline \multirow[t]{3}{*}{+} & - & $\mathrm{C}$ & 2.5 & 0.0 & 0.0 & 0.0 & 0.0 & 0.0 & 2.5 & 67.5 & 0.0 & 2.5 \\
\hline & & $\mathrm{R}$ & 2.5 & 2.5 & 0.0 & 0.0 & 0.0 & 0.0 & 5.0 & 75.0 & 0.0 & 2.5 \\
\hline & & $\mathrm{H}$ & 2.5 & 0.0 & 5.0 & 0.0 & 2.5 & 2.5 & 2.5 & 82.5 & 0.0 & 2.5 \\
\hline- & + & $\mathrm{C}$ & 15.0 & 10.0 & 7.5 & 20.0 & 10.0 & 10.0 & 100.0 & 95.0 & 7.5 & 12.5 \\
\hline \multirow[t]{3}{*}{-} & - & $\mathrm{C}$ & 5.0 & 2.5 & 0.0 & 5.0 & 0.0 & 2.5 & 55.0 & 100.0 & 7.5 & 2.5 \\
\hline & & $\mathrm{R}$ & 2.5 & 0.0 & 5.0 & 2.5 & 2.5 & 10.0 & 60.0 & 90.0 & 25.0 & 12.5 \\
\hline & & $\mathrm{H}$ & 5.0 & 2.5 & 2.5 & 10.0 & 0.0 & 7.5 & 50.0 & 92.5 & 25.0 & 0.0 \\
\hline
\end{tabular}

a Two replicated experiments are shown. Percentages based on 40 seeds.

${ }^{\mathrm{b}}$ Seeds inoculated with soil from Field A; inoculated seeds incubated for $14 \mathrm{~d}$ at $37 \mathrm{C}$ ( salt solution $\mathrm{A}_{\mathrm{w}}=0.96$ ).

${ }^{\mathrm{c}}$ Location on seed where inoculated: $\mathrm{C}=$ center of cotyledon; $\mathrm{R}=$ raphe midway between hilum and chalaza; $\mathrm{H}=$ hilum.

$(72.5 \%)$, corn $(65.0 \%)$, cottonseed $(55.0 \%)$, English walnuts $(47.5 \%)$, and Brazil nuts $(42.5 \%)$. A. niger and $A$. terreus also were prevalent on all commodities, whereas other Aspergillus species were uncommon. Eup. ochrosalmoneum was observed frequently on peanuts $(60.0 \%)$, soybeans $(32.5 \%)$, cottonseed (27.5\%), Brazil nuts $(20.0 \%)$ and corn $(12.5 \%)$, where the species was associated with section Flavi species. In contrast Eup. ochrosalmoneum was rare on English walnuts $(2.5 \%)$ and absent on pistachio nuts and almonds despite a high incidence of species from section Flavi on those seeds. Inoculated corn kernels also had a high incidence of Penicillium species $(42.5 \%)$ that initially were not present on kernels; otherwise colonization by other fungi on seeds was uncommon. Water activities of unwounded, uninoculated seeds and grain $( \pm \mathrm{SD}, \mathrm{n}=10)$ at the end of the experiment $(14 \mathrm{~d})$ ranged from $0.94 \pm$ 0.009 (cottonseed) to $0.96 \pm 0.003$ (peanuts).

Observations on Eup. ochrosalmoneum.-The incidence of Eup. ochrosalmoneum was positively correlated $(P<0.0001$, Pearson product-moment correlation) with both the incidence of seed colonization by Aspergillus section Flavi $(r=82.0)$ and the extent of seed colonization (percentage of the seed surface) by section Flavi ( $r=85.7$ ) based on an examination of peanut seeds from 48 experiments (maximum incubation periods) involving soils from Fields A and B, three temperatures $(22,30,37)$, and eight water activities (0.80-0.98). Small colonies of Eup. ochrosalmoneum were observed sporulating at the inoculated wound site on the peanut seed. As conidiophores of section Flavi species developed on the seed surface, hyphae of Eup. ochrosalmoneum grew upward along the Aspergillus stipes to the exposed surfaces of the Aspergillus heads. Eup. ochrosalmoneum then produced conidium-bearing penicillia on the heads of section Flavi species and formed an expanding colony over the mass of Aspergillus heads (FIGS. 15, 16). In most instances, however, Eup. ochrosalmoneum initially was not observed on the seed but was detected only after section Flavi species had established themselves on the seed. In addition, Eup. ochrosalmoneum often was detected only after conidia from section Flavi species were transferred to $\mathrm{Cz}$ slants for identification and Eup. ochrosalmoneum subsequently sporulated on Aspergillus heads within the slant. Of the 394 seeds with Eup. ochrosalmoneum from the 48 


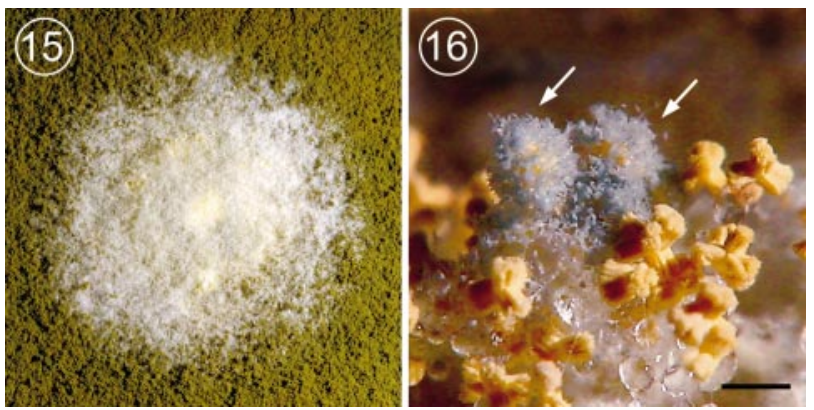

FIGS. 15, 16. Eup. ochrosalmoneum sporulating on the heads of species from Aspergillus section Flavi. Plates of malt extract agar were coinoculated with conidia and incubated at 30 C. 15. A. caelatus colony with sporulating Eup. ochrosalmoneum spreading across the mass of Aspergillus heads. 16. Eup. ochrosalmoneum sporulating on the heads of A. alliaceus, indicated by the arrows. Scale bar $=400$ $\mu \mathrm{m}$.

experiments indicated above, $91.9 \%$ involved sporulation on the heads of section Flavi species and only $8.1 \%$ sporulated directly on the seed in the absence of section Flavi. Eup. ochrosalmoneum occurred at high incidences on $A$. flavus $\mathrm{L}$ and S strains, $A$. parasiticus, A. caelatus and to a lesser extent, A. tamarii. The fungus also sporulated commonly on conidial heads and immature ascostromata of A. alliaceus. In no instance was Eup. ochrosalmoneum observed sporulating on A. niger or other Aspergillus species outside section Flavi or on other genera of fungi. Eup. cinnamopurpureum was observed on only four seeds that were inoculated with soil from Field A, and with those seeds the species sporulated on the heads of $A$. flavus $\mathrm{L}$ strain, A. caelatus, A. tamarii and A. alliaceus in a manner similar to Eup. ochrosalmoneum.

The density of Eup. ochrosalmoneum in soil ( $\pm \mathrm{SD}$; $\mathrm{n}=4)$ was $4077 \pm 2930.0 \mathrm{CFU} / \mathrm{g}$ in Field $\mathrm{A}$ and $27315 \pm 6782.4 \mathrm{CFU} / \mathrm{g}$ in Field B; the relative density (percentage of total filamentous fungi) in Fields $\mathrm{A}$ and $\mathrm{B}$ was $3.1 \pm 1.76$ and $16.7 \pm 6.62$, respectively.

\section{DISCUSSION}

Effect of wounding on fungal colonization.-This research was designed to assess the capacity of fungi to invade living tissues of wounded peanut seeds directly from soil. Rehydrated seeds were used throughout the study because it was determined that they showed similar incidences of colonization by section Flavi and A. niger as seeds from freshly dug pods. Additional experiments showed that wounding was required for extensive colonization of peanut seeds by soil fungi. The low incidence of colonization in viable unwounded seeds supports earlier research showing the importance of injury for invasion by micro-organ- isms and the role of the seed coat as a barrier for invasion (Carter 1973). Tannins, waxes, amino compounds and structural features in the peanut seed coat have been implicated in resistance to invasion by A. flavus and A. parasiticus (Amaya-F et al 1977, LaPrade et al 1973, Sanders and Mixon 1978, Zambettakis and Bockelee-Morvan 1976). Inoculation of different regions of the unwounded peanut seed, including the hilum, which has been postulated as route for A. flavus invasion (Taber et al 1973), had no effect on seed colonization. The few seeds that were colonized extensively might have had cracks or imperfections in the seed coat (Taber et al 1973). These results are in contrast to those of $\mathrm{Xu}$ et al (2000), who reported that peanut seeds are invaded readily by $A$. parasiticus through the seed coat. In the present study inoculation of autoclaved seeds with intact seed coats resulted in increased colonization, suggesting that the inhibitory properties of the seed coat had been partially lost.

Selectivity of peanut seeds for Aspergillus section Flavi.Despite the low soil densities of Aspergillus section Flavi relative to the total numbers of filamentous fungi $(<1 \%)$, peanuts were colonized preferentially by species within the section over much of the water activity and temperature ranges of the study. Incidences of section Flavi species and A. niger were similar in viable and nonviable wounded peanut seeds under conditions (seed $\mathrm{A}_{\mathrm{w}}=0.95$ at $37 \mathrm{C}$ ) that are optimal for colonization but in viable seeds are not conducive to resistance in the form of phytoalexin production (Dorner et al 1989). This suggests that despite the invasion of living tissue, colonization of viable peanut seeds under such conditions has features more characteristic of saprotrophy than a specialized form of parasitism. If the fungus-host relationship is viewed as more saprotrophic than parasitic, then the selectivity of peanut seeds for section Fla$v i$ species and $A$. niger indicates that these species have a high "competitive saprophytic ability" as defined by Garrett (1970) to measure the capacity of a species to achieve dominance in the colonization of dead organic matter. A. terreus appeared at the wound site soon after inoculation and was quickly overrun by section Flavi species and A. niger. Therefore competition with this slow-growing species was minimal. Competition among species within section Flavi and between section Flavi species and A. niger was likely of greater importance, but the extent of this competition and its effect on species composition on seeds are not known. After establishment of section Flavi species and A. niger on peanut seeds, there was little evidence of further successional changes in species composition, with the exception 
of the appearance of Eup. ochrosalmoneum, which might not have been competing directly with the dominant colonists for the peanut substrate.

Competitive saprophytic ability in fungi is complex and depends on environmental variables such as substrate composition, water activity, temperature and inoculum density (Griffin 1972a, Rayner and Webber 1984). Aspergillus species from section Flavi have been reported from diverse substrates but are found most frequently in oil-rich seeds and grains (Diener et al 1987, Payne 1998) where they often have a competitive advantage over other fungi at water activities of $<0.96$ and a temperature of approximately $30 \mathrm{C}$ (Dorner et al 1989, Marín et al 1998a). Although these fungi invaded peanut seeds over wide ranges of water activities and temperatures in the present study, the lengthy incubation required for colonization at suboptimal water activity/temperature combinations typically would not be encountered in the field. Therefore the ranges of water activities and temperatures for colonization of peanuts grown under standard cultivation practices would be much narrower than the ranges shown in this study. Finally, inoculum density determines the probability of a propagule being present in soil at the peanut wound site. Griffin and Garren (1974) estimated that pod infection is possible with as few as 2.0 propagules of A. flavus in the $0.5 \mathrm{~mm}$ layer of the geocarposphere. The precise relationship between soil population density and the incidence of colonization in wounded seeds currently is being examined.

In addition to environmental parameters, physiological characters such as rate of spore germination, rate of mycelial growth and enzymatic capability greatly influence competitive saprophytic ability in fungi (Garrett 1970). Conidia of A. flavus do not germinate in the peanut geocarposphere due to soil fungistasis (Griffin 1972b). However injury to the pod releases sugars and amino-N compounds that let conidia overcome fungistasis and to germinate at high percentages (Hale and Griffin 1976). The production of diverse enzymes for degrading plant components such as cellulose, pectin, lignin and lipids (Betts and Dart 1989, Cotty et al 1990, Long et al 1998, Olutiola 1976) also likely contributes to the competitive advantage of section Flavi species in invading peanut seeds.

In this study seeds and grain other than peanuts also were colonized readily by section Flavi species when wounded and inoculated with soil. Instances of exposure of these aerial crops to airborne dust (Doster and Michailides 1994, Lee et al 1986) and to soil when plants are downed by wind or harvesting equipment (Doster and Michailides 1994, Zummo and Scott 1990) have led to colonization by A. flavus; oth- erwise aerial crops are typically not in contact with soil. Infection of aerial crops instead occurs primarily through wind and insect dispersal of conidia, and wounding greatly enhances colonization by A. flavus and aflatoxin contamination (Diener et al 1987, Payne 1998). A mixture of species at the wound site, whether aerially dispersed by wind/insects or applied as soil, likely would result in selection for section Flavi species under moisture and temperature conditions favorable for these fungi.

Interactions of water activity and temperature.-Conditions for peanut seed colonization by section Flavi species in the current study (ranges: $\mathrm{A}_{\mathrm{w}}=0.82-0.98$ and $15-37 \mathrm{C}$; optima: $\mathrm{A}_{\mathrm{w}}=0.92-0.96$ at $22-37 \mathrm{C}$ ) were similar to conditions reported for spore germination and growth in pure culture (Holmquist et al 1983, Pitt and Miscamble 1995, Mislivec et al 1975, Sautour et al 2002). The observation of greater tolerance for low water activities at temperatures optimal for growth also has been reported from controlled culture conditions (Ayerst 1969, Holmquist et al 1983, Mislivec et al 1975, Pitt and Miscamble 1995). Water activities $\geq 0.98$ are suboptimal for growth of section Flavi species (Pitt and Miscamble 1995, Sautour et al 2002), which was evident in the current experiments at the highest seed water activity of 0.98 . However phytoalexin production by injured peanut seeds also is optimal at high water activities (Dorner et al 1989, Wotton and Strange 1987) and this might account for the inhibition of all fungal species observed at wound sites at the highest water activity. Peanut seeds under field conditions are most susceptible to invasion by A. flavus and aflatoxin contamination at water activities of $0.90-0.95$ because above this range phytoalexins are inhibitory to $A$. $f l a-$ vus and below this range the reduced water activity restricts fungal growth (Dorner et al 1989).

$A$. niger was the dominant colonist of wounded peanut seeds outside Aspergillus section Flavi. This species has moisture and temperature requirements that are slightly broader than those of $A$. flavus and grows faster (Ayerst 1969, Marín et al 1998b). A. niger and A. flavus commonly co-occur on agricultural commodities such as peanuts, corn, cottonseed and tree nuts (Abdulla 1974, Ashworth et al 1971, Austwick and Ayerst 1963, Bayman et al 2002b, Hesseltine et al 1981, Hill et al 1983, Joffe 1969). Other Aspergillus species were less prominent on peanut seeds. A. terreus and Em. rugulosa, present at the early successional stages of peanut seed colonization, were limited in growth by the more aggressive section Flavi species and $A$. niger. However, because of their higher temperature ranges for growth (Ayerst 1969), A. terreus and Em. rugulosa were capable of extensively col- 
onizing peanut seeds at $45 \mathrm{C}$ in the absence of other Aspergillus competitors.

Other fungal species colonized seeds primarily at water activities and temperatures suboptimal for section Flavi species and A. niger. The majority of these species has been reported previously from freshly harvested peanut seeds, with dominant genera comprising Aspergillus, Penicillium and Fusarium (Hanlin 1973, Joffe 1969, Pettit and Taber 1968). Fungal species were detected and identified in this study by their aerial growth and sporulation on the surfaces of peanut seeds. The extent to which species were confined to the internal tissues of seeds and remained undetected is not known.

Conditions resulting in the highest incidences of Penicillium species and their teleomorphs on peanut seeds in the present study fell into four categories: (i) low water activities and cool to moderate temperatures (majority of species); (ii) high water activities and moderate temperatures (Pen. pinophilum and Pen. funiculosum); (iii) high water activities and high temperatures (Talaromyces species); and (iv) moderate water activities and moderate temperatures (Eup. ochrosalmoneum). These generalized conditions were consistent with reported optima for spore germination and growth of Penicillium species under culture conditions (Hocking and Pitt 1979, Mislivec and Tuite 1970, Pitt 1979), although data for many of the species are absent or incomplete. Fusarium and Clonostachys species colonized peanut seeds primarily at high water activities and cool temperatures, and these conditions also were consistent with reports of maximum growth of Fusarium species at water activities $>0.98$ and temperatures near $25 \mathrm{C}$ (Magan and Lacey 1984, Marín et al 1995).

Notably absent on peanut seeds in the present study were peanut pathogens prevalent in southern Georgia such as Rhizoctonia solani, Sclerotium rolfsii (white mold) and Macrophomina phaseolina (charcoal rot), species that infect peanut seeds through hyphal growth from infested plant debris and through myceliogenic germination of sclerotia (Kokalis-Burelle et al 1997). The absence of these pathogens might reflect the low probability of propagules being present in the small amount of soil applied to the seed wound. On the other hand, the experimental conditions might not have been conducive for colonization by these fungi.

Crop specificity in A. parasiticus.-Past research does not adequately explain why peanuts are more frequently infected by $A$. parasiticus than aerial crops such as corn and cottonseed in which A. flavus is the predominant aflatoxigenic species (Diener et al 1987, Hill et al 1985, Horn 2003). Angle et al (1982) and Horn et al (1995) reported approximately equal proportions of A. flavus and A. parasiticus in soil from cornfields in Missouri and Georgia respectively, yet corn from these regions is infected primarily by A. flavus. Soil insects harbor both species and are capable of vectoring them to aerial crops (Lillehoj et al 1980), suggesting that selection for A. flavus likely occurs in the crop. A. parasiticus readily colonizes corn ears that are artificially wounded and inoculated with A. parasiticus alone (Wilson et al 1986, Zummo and Scott 1990), but competition greatly favors $A$. flavus when ears are co-inoculated with the two species (Calvert et al 1978).

This study showed that the incidence of peanut seed colonization by $A$. parasiticus was optimal at 22 C compared to 30-37 C for A. flavus. Furthermore, when peanut seeds were incubated for extended periods at $15 \mathrm{C}, A$. parasiticus was the only species from section Flavi to colonize seeds. A. parasiticus grows more rapidly at 22-25 $\mathrm{C}$ than $A$. flavus on culture media (Pitt and Miscamble 1995) and irradiated pecans (Váquez-Barrios et al 2001), and aflatoxin production is greatest in $A$. parasiticus at $25 \mathrm{C}$ as opposed to $30 \mathrm{C}$ for A. flavus (Faraj et al 1991). Overall temperature differences between subterranean peanut pods and aerial corn and cotton fruits in part might account for the preferential infection of peanuts by $A$. parasiticus. In water-stressed peanut plants grown in southern Georgia, soil and pod temperatures were 23-28 $\mathrm{C}$ and 19-31 C respectively, whereas aerial stem temperatures reached a maximum of 4045 C (6-10 G greater than air temperature) (Sanders et al 1985a). Temperatures within corn ears and cotton bolls also often exceed daytime air temperatures by at least several degrees (Anderson 1940, Chu and Bariola 1987, Khabba et al 2001). Therefore elevated temperatures at potential infection sites on corn and cotton might give $A$. flavus a competitive advantage over A. parasiticus.

Association of Eupenicillium species with Aspergillus section Flavi.-There have been sporadic reports of Penicillium species within subgenus Biverticillium (Pen. purpurogenum and Pen. rugulosum) parasitizing and sporulating on the heads of $A$. niger and occasionally section Flavi species (A. tamarii, A. flavus and A. oryzae) (Raper and Thom 1949, Tatarenko 1959), but this paper is the first report of Eupenicillium species showing a similar growth habit. Furthermore the present research suggests some degree of specificity of Eup. ochrosalmoneum and Eup. cinnamopurpureum for Aspergillus species belonging to section Flavi. The precise nature of this association and whether parasitism is involved remain to be determined. Because Eup. ochrosalmoneum was capable of 
colonizing peanut seeds in the absence of section Fla$v i$, this association, regardless of its nutritional basis, is clearly facultative. Colonization of the substrate by Eup. ochrosalmoneum might be required for subsequent sporulation on Aspergillus heads, which is one possible explanation for the failure of Eup. ochrosalmoneum to establish itself on section Flavi species sporulating on pistachio nuts and almonds.

Eupenicillium species are isolated primarily from soil (Stolk and Samson 1983). However both Eup. ochrosalmoneum and Eup. cinnamopurpureum have been reported frequently from seeds and grains (Pitt 1979, Stolk and Samson 1983). Eup. ochrosalmoneum invades preharvest corn (Wicklow and Cole 1984, Wicklow et al 1984, Wicklow et al 1988) and peanuts (B.W. Horn unpublished data), where it produces the neurotoxic mycotoxin citreoviridin, and Eup. cinnamopurpureum has been reported from corn in storage (Wicklow et al 1998). Aspergillus species from section Flavi are common on these substrates and likely would compete with Eup. ochrosalmoneum and Eup. cinnamopurpureum. In this study the relatively slowgrowing Eupenicillium species sporulated close to the substrate and were overrun quickly by more aggressive section Flavi species that produced much taller conidiophores. A long history of interactions between the two groups of fungi might have resulted in an adaptation in which Eupenicillium species sporulate on the heads of section Flavi species for efficient aerial dispersal of their conidia.

The high frequency of Eup. ochrosalmoneum associated with section Flavi on peanut seeds might be due to the abundance of the species in soil, with densities in the current study of up to $3.6 \times 10^{4} \mathrm{CFU} / \mathrm{g}$. Eup. ochrosalmoneum produces immature ascostromata on preharvest corn (Wicklow et al 1984) and peanuts (B.W. Horn unpublished data). Immature ascostromata in corn are dispersed to the soil surface by combine harvesters (Wicklow et al 1984) and subsequently mature to form ascospores (Horn and Wicklow 1986). An accumulation of resistant ascospores over many growing seasons could account for the high soil populations.

Conclusions.-Wounding of peanut seeds and inoculation of the wounds with soil in the laboratory have parallels with activities in nature; for example, the sudden exposure of a resource base when an insect creates a peanut wound that is contact with the surrounding soil. Furthermore, there are similarities between species composition on seeds in this study and reported species from peanuts in the field. A comparison between the incidence of seed colonization in the laboratory and in nature is difficult, but a higher incidence under laboratory conditions would be expected due to the highly controlled conditions. Despite the dissimilarities with infection of peanuts under field cultivation, inoculation of wounded viable peanut seeds with soil containing natural populations of fungi provides a model system for studying the infection process, the interactions among fungi and those factors important in aflatoxin formation.

\section{ACKNOWLEDGMENTS}

Appreciation is given to Travis Walk (USDA-ARS) for his technical assistance, to Victor Sobolev (USDA-ARS) for assistance with the photography and to Wayne Guerke (Georgia Department of Agriculture) for performing the tetrazolium tests for peanut seed viability. Ron Sorensen (USDAARS) kindly provided peanut fields for pod collections; Tom Schatzki (USDA-ARS) provided almonds, pistachio nuts and English walnuts; and Don Wicklow (USDA-ARS) provided corn kernels.

\section{LITERATURE CITED}

Abdalla MH. 1974. Mycoflora of groundnut kernels from the Sudan. Trans Br Mycol Soc 63:353-359.

Amaya-F J, Young CT, Mixon AC, Norden AJ. 1977. Soluble amino and carbohydrate compounds in the testae of six experimental peanut lines with various degrees of Aspergillus flavus resistance. J Agric Food Chem 25: 661-663.

Anderson DB. 1940. The internal temperature of cotton bolls. Amer J Bot 27:43-51.

Angle JS, Dunn KA, Wagner GH. 1982. Effect of cultural practices on the soil population of Aspergillus flavus and Aspergillus parasiticus. Soil Sci Soc Amer J 46:301304.

Ashworth LJJr, Rice RE, McMeans JL, Brown CM. 1971. The relationship of insects to infection of cotton bolls by Aspergillus flavus. Phytopathology 61:488-493.

Austwick PKC, Ayerst G. 1963. Groundnut microflora and toxicity. Chem Ind 41:55-61.

Ayerst G. 1969. The effects of moisture and temperature on growth and spore germination in some fungi. J Stored Prod Res 5:127-141.

Bayman P, Baker JL, Doster MA, Michailides TJ, Mahoney NE. 2002a. Ochratoxin production by the Aspergillus ochraceus group and Aspergillus alliaceus. Appl Environ Microbiol 68:2326-2329.

— — - Mahoney NE. 2002b. Aspergillus on tree nuts: incidence and associations. Mycopathologia 155: 161-169.

Betts WB, Dart RK. 1989. Initial reactions in degradation of tri- and tetrameric lignin-related compounds by Aspergillus flavus. Mycol Res 92:177-181.

Blankenship PD, Cole RJ, Sanders TH, Hill RA. 1984. Effect of geocarposphere temperature on pre-harvest colonization of drought-stressed peanuts by Aspergillus flavus and subsequent aflatoxin contamination. Mycopathologia 85:69-74.

Calvert OH, Lillehoj EB, Kwolek WF, Zuber MS. 1978. Af- 
latoxin $\mathrm{B}_{1}$ and $\mathrm{G}_{1}$ production in developing Zea mays kernels from mixed inocula of Aspergillus flavus and A. parasiticus. Phytopathology 68:501-506.

Carter JBH. 1973. The influence of the testa, damage and seed dressing on the emergence of groundnut (Arachis hypogaea). Ann Appl Biol 74:315-323.

Chirife J, Resnik SL. 1984. Unsaturated solutions of sodium chloride as reference sources of water activity at various temperatures. J Food Sci 49:1486-1488.

Chu C-C, Bariola LA. 1987. Survival of pink bollworm, Pectinophora gossypiella (Saunders), larvae in green cotton bolls at high internal boll temperatures. Southwest Entomol 12:271-277.

Cotty PJ. 1989. Virulence and cultural characteristics of two Aspergillus flavus strains pathogenic on cotton. Phytopathology 79:808-814.

—, Cleveland TE, Brown RL, Mellon JE. 1990. Variation in polygalacturonase production among Aspergillus flavus isolates. Appl Environ Microbiol 56:38853887.

Craufurd PQ, Prasad PVV, Kakani VG, Wheeler TR, Nigam SN. 2003. Heat tolerance in groundnut. Field Crops Res 80:63-77.

Diener UL, Cole RJ, Sanders TH, Payne GA, Lee LS, Klich MA. 1987. Epidemiology of aflatoxin formation by Aspergillus flavus. Ann Rev Phytopathol 25:249-270.

Domsch KH, Gams W, Anderson T-H. 1980. Compendium of soil fungi. Vol. 1. London: Academic Press. 859 p.

Dorner JW, Cole RJ, Sanders TH, Blankenship PD. 1989. Interrelationship of kernel water activity, soil temperature, maturity, and phytoalexin production in preharvest aflatoxin contamination of drought-stressed peanuts. Mycopathologia 105:117-128.

Doster MA, Michailides TJ. 1994. Development of Aspergillus molds in litter from pistachio trees. Plant Dis 78: 393-397.

Dowell FE, Dorner JW, Cole RJ, Davidson JI Jr. 1990. Aflatoxin reduction by screening farmers stock peanuts. Peanut Sci 17:6-8.

Ellis MB. 1971. Dematiaceous hyphomycetes. Kew, Surrey, England: Commonwealth Mycological Institute. 608 p.

Faraj MK, Smith JE, Harran G. 1991. Interaction of water activity and temperature on aflatoxin production by $A s$ pergillus flavus and $A$. parasiticus in irradiated maize seeds. Food Addit Contam 8:731-736.

Garrett SD. 1970. Pathogenic root-infecting fungi. Cambridge, England: Cambridge University Press. 294 p.

Griffin DM. 1972a. Ecology of soil fungi. Syracuse, New York: Syracuse University Press. 193 p.

Griffin GJ. 1972b. Conidial germination and population of Aspergillus flavus in the geocarphosphere of peanut. Phytopathology 62:1387-1391.

— - Garren KH. 1974. Population levels of Aspergillus flavus and A. niger group in Virginia peanut field soils. Phytopathology 64:322-325.

Guillebeau P, Ed. 2004. Georgia pest management handbook. Special Bulletin 28. Athens, Georgia: University of Georgia College of Agricultural and Environmental Sciences. 716 p.

Hale MG, Griffin GJ. 1976. The effect of mechanical injury on exudation from immature and mature peanut fruits under axenic conditions. Soil Biol Biochem 8:225-227.

Hanlin RT. 1973. The distribution of peanut fungi in the southeastern United States. Mycopathol Mycol Appl 49: 227-241.

Hesseltine CW, Rogers RF, Shotwell OL. 1981. Aflatoxin and mold flora in North Carolina in 1977 corn crop. Mycologia 73:216-228.

Hill RA, Blankenship PD, Cole RJ, Sanders TH. 1983. Effects of soil moisture and temperature on preharvest invasion of peanuts by the Aspergillus flavus group and subsequent aflatoxin development. Appl Environ Microbiol 45:628-633.

, Wilson DM, McMillian WW, Widstrom NW, Cole RJ, Sanders TH, Blankenship PD. 1985. Ecology of the Aspergillus flavus group and aflatoxin formation in maize and groundnut. In: Lacey J, ed. Trichothecenes and other mycotoxins. Chichester, United Kingdom: John Wiley and Sons. p 79-95.

Hocking AD, Pitt JI. 1979. Water relations of some Penicillium species at 25 C. Trans Br Mycol Soc 73:141-145.

Holmquist GU, Walker HW, Stahr HM. 1983. Influence of temperature, $\mathrm{pH}$, water activity and antifungal agents on growth of Aspergillus flavus and A. parasiticus. J Food Sci 48:778-782.

Horn BW. 1997. Aspergillus caelatus, a new species in section Flavi. Mycotaxon 61:185-191.

2003. Ecology and population biology of aflatoxigenic fungi in soil. J Toxicol-Toxin Rev 22:351-379.

— Dorner JW. 1998. Soil populations of Aspergillus species from section Flavi along a transect through peanut-growing regions of the United States. Mycologia 90:767-776.

, - Greene RL, Blankenship PD, Cole RJ. 1994. Effect of Aspergillus parasiticus soil inoculum on invasion of peanut seeds. Mycopathologia 125:179-191.

, Greene RL. 1995. Vegetative compatibility within populations of Aspergillus flavus, A. parasiticus, and A. tamarii from a peanut field. Mycologia 87:324-332.

- Dorner JW. 1995. Effect of corn and peanut cultivation on soil populations of Aspergillus flavus and A. parasiticus in southwestern Georgia. Appl Environ Microbiol 61:2472-2475.

- — Sobolev VS, Dorner JW, Powell JH, Layton RC. 1996. Association of morphology and mycotoxin production with vegetative compatibility groups in Aspergillus flavus, A. parasiticus, and A. tamarii. Mycologia 88:574-587.

- Wicklow DT. 1986. Ripening of Eupenicillium ochrosalmoneum ascostromata on soil. Mycologia 78:248252.

Joffe AZ. 1969. The mycoflora of fresh and stored groundnut kernels in Israel. Mycopathol Mycol Appl 39:255264.

Khabba S, Ledent J-F, Lahrouni A. 2001. Maize ear temperature. Eur J Agron 14:197-208.

Klich MA. 2002. Identification of common Aspergillus species. Utrecht, The Netherlands: Centraalbureau voor Schimmelcultures. $116 \mathrm{p}$.

Kokalis-Burelle N, Porter DM, Rodríguez-Kábana R, Smith 
DH, Subrahmanyam P, Eds. 1997. Compendium of peanut diseases. 2nd ed. St. Paul, Minnesota: APS Press. $94 \mathrm{p}$.

Lamb MC, Sternitzke DA. 2001. Cost of aflatoxin to the farmer, buying point, and sheller segments of the Southeast United States peanut industry. Peanut Sci 28: 59-63.

LaPrade JC, Bartz JA, Norden AJ, Demuynk TJ. 1973. Correlation of peanut seed-coat surface wax accumulations with tolerance to colonization by Aspergillus flavus. J Amer Peanut Res Educ Soc 5:89-94.

Lee LS, Lee LV Jr, Russell TE. 1986. Aflatoxin in Arizona cottonseed: field inoculation of bolls by Aspergillus flavus spores in wind-driven soil. JAOCS 63:530-532.

Lillehoj EB, McMillian WW, Guthrie WD, Barry D. 1980. Aflatoxin-producing fungi in preharvest corn: inoculum source in insects and soils. J Environ Qual 9:691694.

Long K, Ghazali HM, Ariff A, Man YC, Bucke C. 1998. Substrate preference of mycelium-bound lipase from a strain of Aspergillus flavus Link. Biotechnol Lett 20: 369-372.

Lynch RE. 1984. Damage and preference of lesser cornstalk borer (Lepidoptera: Pyralidae) larvae for peanut pods in different stages of maturity. J Econ Entomol 77:360 363.

- Mack TP. 1995. Biological and biotechnical advances for insect management in peanut. In: Pattee HE, Stalker HT, eds. Advances in peanut science. Stillwater, Oklahoma: American Peanut Research and Education Society. p 95-159.

—, Wilson DM. 1991. Enhanced infection of peanut, Arachis hypogaea L., seeds with Aspergillus flavus group fungi due to external scarification of peanut pods by the lesser cornstalk borer, Elasmopalpus lignosellus (Zeller). Peanut Sci 18:110-116.

Magan N, Lacey J. 1984. Water relations of some Fusarium species from infected wheat ears and grain. Trans $\mathrm{Br}$ Mycol Soc 83:281-285.

Marín S, Sanchis V, Magan N. 1995. Water activity, temperature, and $\mathrm{pH}$ effects on growth of Fusarium monilifor$m e$ and Fusarium proliferatum isolates from maize. Can J Microbiol 41:1063-1070.

- — Ramos AJ, Vinas I, Magan N. 1998a. Environmental factors, in vitro interactions, and niche overlap between Fusarium moniliforme, F. proliferatum, and F. graminearum, Aspergillus and Penicillium species from maize grain. Mycol Res 102:831-837.

— — Sáenz R, Ramos AJ, Vinas I, Magan N. 1998b. Ecological determinants for germination and growth of some Aspergillus and Penicillium spp. from maize grain. J Appl Microbiol 84:25-36.

Mislivec PB, Dieter CT, Bruce VR. 1975. Effect of temperature and relative humidity on spore germination of mycotoxic species of Aspergillus and Penicillium. Mycologia 67:1187-1189.

— requirements of species of Penicillium isolated from yellow dent corn kernels. Mycologia 62:75-88.

Nelson PE, Toussoun TA, Marasas, WFO. 1983. Fusarium species: an illustrated manual for identification. University Park: The Pennsylvania State University Press. $193 \mathrm{p}$.

Olutiola PO. 1976. Cellulase enzymes in culture filtrates of Aspergillus flavus. Trans Br Mycol Soc 67:265-268.

Payne GA. 1998. Process of contamination by aflatoxin-producing fungi and their impact on crops. In: Sinha KK, Bhatnagar D, eds. Mycotoxins in agriculture and food safety. New York: Marcel Dekker. p 279-306.

Peters J, ed. 2000. Tetrazolium testing handbook. Contribution no. 29 to the handbook on seed testing. Lincoln, Nebraska: Association of Official Seed Analysts. $302 \mathrm{p}$.

Peterson SW. 2000. Phylogenetic relationships in Aspergillus based on RDNA sequence analysis. In: Samson RA, Pitt JI, eds. Integration of modern taxonomic methods for Penicillium and Aspergillus classification. Amsterdam, The Netherlands: Harwood Academic Publishers. p 323-355.

Pettit RE, Taber RA. 1968. Factors influencing aflatoxin accumulation in peanut kernels and the associated mycoflora. Appl Microbiol 16:1230-1234.

Pitt JI. 1979. The genus Penicillium and its teleomorphic states Eupenicillium and Talaromyces. London: Academic Press. 634 p.

— Miscamble BF. 1995. Water relations of Aspergillus flavus and closely related species. J Food Prot 58:8690.

Porter DM, Wright FS, Steele JL. 1986. Relationship of microscopic shell damage to colonization of peanut by Aspergillus flavus. Oléagineux 41:23-27.

Raper KB, Fennell DI. 1965. The genus Aspergillus. Baltimore, Maryland: Williams and Wilkins. 686 p.

—, Thom C. 1949. A manual of the penicillia. Baltimore, Maryland: Williams and Wilkins. $875 \mathrm{p}$.

Rayner ADM, Webber JF. 1984. Interspecific mycelial interactions-an overview. In: Jennings DH, Rayner ADM, eds. The ecology and physiology of the fungal mycelium. Cambridge, England: Cambridge University Press. p 383-417.

Saito M, Tsuruta O. 1993. A new variety of Aspergillus flavus from tropical soil in Thailand and its aflatoxin productivity. Proc Jap Assoc Mycotoxicol 37:31-36.

Samson RA. 1974. Paecilomyces and some allied hyphomycetes. Stud Mycol 6:1-119.

Sanders TH, Blankenship PD, Cole RJ, Hill RA. 1985a. Temperature relationships of peanut leaf canopy, stem, and fruit in soil of varying temperature and moisture. Peanut Sci 12:86-89.

, Cole RJ, Blankenship PD, Hill RA. 1985b. Relation of environmental stress duration to Aspergillus flavus invasion and aflatoxin production in preharvest peanuts. Peanut Sci 12:90-93.

, Hill RA, Cole RJ, Blankenship PD. 1981. Effect of drought on occurrence of Aspergillus flavus in maturing peanuts. J Amer Oil Chem Soc 58:966A-970A.

— Mixon AC. 1978. Effect of peanut tannins on percent seed colonization and in vitro growth by Aspergillus parasiticus. Mycopathologia 66:169-173.

Sautour M, Mansur CS, Divies C, Bensoussan M, Dantigny 
P. 2002. Comparison of the effects of temperature and water activity on growth rate of food spoilage moulds. J Ind Microbiol Biotechnol 28:311-315.

Schipper MAA, Stalpers JA. 1984. A revision of the genus Rhizopus. II. The Rhizopus microsporus-group. Stud Mycol 25:20-34.

Schroeder HW, Ashworth, LJ Jr. 1965. Aflatoxins in Spanish peanuts in relation to pod and kernel conditions. Phytopathology 55:464-465.

Schroers H-J. 2001. A monograph of Bionectria (Ascomycota, Hypocreales, Bionectriaceae) and its Clonostachys anamorphs. Stud Mycol 46:1-214.

Stolk AC, Samson RA. 1983. The ascomycete genus Eupenicillium and related Penicillium anamorphs. Stud Mycol 23:1-149.

Subrahamanyam A, Mehrotra BS, Thirumalachar MJ. 1977. Thermomucor-a new genus of Mucorales. Georgia J Sci 35:1-4.

Taber RA, Pettit RE, Benedict CR, Dieckert JW, Ketring DL. 1973. Comparison of Aspergillus flavus tolerant and susceptible peanut lines I. Light microscope investigation. J Amer Peanut Res Educ Assoc 5:206-207.

Tatarenko ES. 1959. Parasitism of mold fungi. Mikrobiologiya 28:887-893.

Váquez-Barrios ME, Martínez-Peniche R, Fernández-Escartín E. 2001. Development of toxigenic Aspergillus flavus and A. parasiticus on kernels of native pecan [Carya illinoensis (Wangenh) K. Koch] genotypes under different water activities. Sci Hort 89:155-169.

Wicklow DT, Cole RJ. 1984. Citreoviridin in standing corn infested by Eupenicillium ochrosalmoneum. Mycologia 76:959-961.

—, Horn BW, Burg WR, Cole RJ. 1984. Sclerotium dispersal of Aspergillus flavus and Eupenicillium ochrosalmoneum from maize during harvest. Trans $\mathrm{Br}$ Mycol Soc 83:299-303.

_ Stubblefield RD, Horn BW, Shotwell OL. 1988. Ci- treoviridin levels in Eupenicillium ochrosalmoneum-infested maize kernels at harvest. Appl Environ Microbiol 54:1096-1098.

, Weaver DK, Throne JE. 1998. Fungal colonists of maize grain conditioned at constant temperatures and humidities. J Stored Prod Res 34:355-361.

Wild CP, Turner PC. 2002. The toxicology of aflatoxins as a basis for public health decisions. Mutagenesis 17:471481.

Williams EJ, Drexler JS. 1981. A non-destructive method for determining peanut pod maturity. Peanut Sci 8:134141.

— Monroe GE. 1986. Impact blasters for peanut pod maturity determination. Trans Amer Soc Agric Eng 29: 263-266, 275.

Wilson DM, McMillian WW, Widstrom N. 1986. Use of Aspergillus flavus and $A$. parasiticus color mutants to study aflatoxin contamination of corn. In: Barry S, Houghton DR, Llewellyn GC, O'Rear CE, eds. Biodeterioration 6. Slough, United Kingdom: CAB International. p 284-288.

Wotton HR, Strange RN. 1987. Increased susceptibility and reduced phytoalexin accumulation in drought-stressed peanut kernels challenged with Aspergillus flavus. Appl Environ Microbiol 53:270-273.

Xu H, Annis S, Linz J, Trail F. 2000. Infection and colonization of peanut pods by Aspergillus parasiticus and the expression of the aflatoxin biosynthetic gene, nor-1, in infection hyphae. Physiol Mol Plant Pathol 56:185-196.

Zambettakis C, Bockelee-Morvan A. 1976. Recherches sur la structure du tégument séminal de la graine d'arachide et son influence sur la pénétration de l'Aspergillus flavus. Oléagineux 31:219-228.

Zheng R-Y, Chen G-Q. 2001. A monograph of Cunninghamella. Mycotaxon 80:1-75.

Zummo N, Scott GE. 1990. Relative aggressiveness of Aspergillus flavus and A. parasiticus on maize in Mississippi. Plant Dis 74:978-981. 